\title{
Transport demand management and energy consumption in urban areas
}

\author{
S. Basbas \\ Department of Transportation and Hydraulic Engineering, \\ Faculty of Rural and Surveying Engineering, School of Technology, \\ Aristotle University of Thessaloniki, Greece
}

\begin{abstract}
Within the framework of this paper, the impact of various transport demand management (TDM) strategies, designed for urban central areas, to fuel consumption is examined and evaluated through the use of the traffic simulation and assignment model SATURN. TDM strategies examined include high occupancy vehicle (HOV) lanes, bus lanes (with flow and contra-flow) and schemes for pedestrian-only streets and bus-only streets. The modeling results have been quite encouraging, in most cases.

Keywords: transport demand management, fuel consumption, HOV lanes, bus lanes, pedestrian streets.
\end{abstract}

\section{Introduction}

The level of service offered by the transport system significantly affects people's daily lives worldwide. The problem becomes more important in the case of urban central areas due to the fact that transport demand usually exceeds transport supply. Among the key factors of the problem in central urban areas is the constant increase in the number and use of passenger cars, the insufficient operation of the public transport system in many cases, the high population and building density, the limited offer of parking lots on-street and off-street etc. Therefore it is obvious that demand plays a dominant role since supply is not always easy to change due to specific constraints (e.g., limited space for new infrastructure) and budget availability. This is the reason why an extensive effort has been made during the last years in order to affect the transport demand in central urban areas through the implementation of strategies known as transport 
demand management (TDM) strategies. These strategies have an impact not only to transport demand but also to the environment (e.g., emissions, fuel consumption etc.). Moreover the interconnection of the transport system with the environment is well known. One of the most important impacts of the transport system to the environment has to do with the energy consumption.

The transport sector is a main energy consumer worldwide. For example, energy consumption by sector (in Mtoe, where toe is tonne of oil equivalent - a tonne of oil with a net calorific value of 41868 kilojoules $/ \mathrm{kg}$ ) in the EU-25 for the year 2003 is as follows [1]:

- Domestic and Tertiary: $\quad 40 \%$

- Transport: $31 \%$

- Industry: $29 \%$

Therefore it becomes obvious that a well organised transport system will have a significant effect on fuel consumption and environment in general. Within the framework of this paper an attempt has been made to investigate the impact of TDM on fuel consumption in urban road networks. The case studies presented in the paper refer to the cities of Thessaloniki and Komotini, Greece and the TDM examined include with-flow and contra-flow bus lanes, High-Occupancy Vehicle (HOV) lanes, pedestrian-only streets and bus-only streets. The traffic simulation and assignment model used in the case studies in order to evaluate various road network performance indicators is the SATURN model.

\section{TDM strategies under consideration}

TDM includes HOV lanes, high-occupancy toll (HOT) lanes, bus lanes (withflow and contra-flow), parking pricing etc. It must be mentioned at this point that TDM can efficiently support the effort towards a sustainable transportation system.

As it was previously mentioned the specific TDM strategies presented in the framework of this paper include with-flow and contra-flow bus lanes, HOV lanes, pedestrian-only streets and bus-only streets. With-flow bus lanes and contra-flow bus lanes are lanes restricted to buses (but other road users like drivers of high occupancy vehicles, emergency vehicles etc. are possibly entitled to use these lanes) [2]. A with-flow lane is the most traditional bus priority measure worldwide. Bus gates and rising bollards tend to be considered when access to a particular street is to be restricted to buses [2].

An HOV lane is a lane where private cars can enter only if an occupancy requirement is met (e.g., more than 2 or 3 passengers in the car). According to the Online TDM Encyclopedia [3] "HOV Priority is a major component of many regional TDM programs. HOV priority refers to strategies that give priority to HOVs (also called Ridershare Vehicles), including transit buses, vanpools and carpools. Two, three or four occupants (indicated as $2+, 3+$ or $4+$ ) may be required to be considered as HOV, depending on the circumstances". 


\section{Presentation of the case studies}

\subsection{Proposed HOV lanes in the city of Thessaloniki}

Thessaloniki is the second largest city in Greece with a population of around one million inhabitants and is located in the northern part of the country. The city is characterized by severe traffic and environmental associated problems especially in the central area. The use of Public Transport buses is steadily decreasing while at the same time there is a parallel increase in the number and use of passenger cars. Two major transport infrastructure projects are foreseen to be completed in the next 5 to 7 years (a $9.6 \mathrm{~km}$ metro line and a submerged tunnel). In the meantime a number of TDM are examined (and some of them have been already implemented) in order to confront the problems in the medium-term horizon.

One of the transport demand management measures include the implementation of High Occupancy Vehicle (HOV) lanes. Such a measure does not exist at present in the city. However various scenarios including the implementation of HOV lanes in the city road network are examined through the use of the traffic simulation and assignment model SATURN in the framework of the EU project ICARO [4] and in the framework of a research in the Faculty of Rural and Surveying Engineering, Aristotle University of Thessaloniki [5]. The results of these scenarios as far as their impact to fuel consumption is concerned are presented hereinafter.

In the framework of the project ICARO [4] the HOV lane was chosen to be a contra-flow lane along a main one-way arterial road (outbound direction) connecting the city centre with the eastern part of the city. The length of the under examination HOV lane was $3.5 \mathrm{~km}$. The longer the length of the HOV lane is, the greater the benefits are, in terms of time savings and operational cost.

Three different scenarios were formulated and tested with the aid of a traffic simulation and assignment model. The model that was used for the purposes of this study was SATURN (Simulation and Assignment of Traffic to Urban Road Networks), which is a suite of flexible network analysis program developed at the Institution for Transport Studies, University of Leeds, UK. SATURN is a combined traffic simulation and assignment model for the analysis of traffic management schemes over relatively localised networks.

Table 1: Network-based comparative evaluation results for the $3 \mathrm{HOV}$ scenarios.

\begin{tabular}{|c|c|c|c|c|}
\hline Scenarios & $\begin{array}{c}\text { Basic } \\
\text { scenario } \\
\text { (existing } \\
\text { situation) }\end{array}$ & $\begin{array}{c}\text { 1st scenario } \\
\text { (HOV lane } \\
\text { for passenger } \\
\text { cars) }\end{array}$ & $\begin{array}{c}\text { 2nd scenario } \\
\text { (HOV lane }+ \\
\text { parking } \\
\text { station) }\end{array}$ & $\begin{array}{c}\text { 3rd scenario } \\
\text { (HOV lane } \\
\text { for passenger } \\
\text { cars and } \\
\text { buses) }\end{array}$ \\
\hline $\begin{array}{c}\text { Fuel } \\
\text { consumption } \\
\text { (lit) }\end{array}$ & 104,624 & $\begin{array}{c}-984 \\
(+0.9 \%)\end{array}$ & $\begin{array}{c}-2,106 \\
(+2 \%)\end{array}$ & $\begin{array}{c}-3,121 \\
(+3 \%)\end{array}$ \\
\hline
\end{tabular}

Source: [4]. 
The first scenario includes the construction of $3.5 \mathrm{~km} \mathrm{HOV}$ lane. In the second scenario a parking station is foreseen at the entrance of the HOV lane in order to attract drivers who would like to be car poolers (park and ride facility). Finally, both passenger cars and Public Transport buses use the HOV lane in the third scenario. The network-based comparative evaluation results for the three scenarios, as far as fuel consumption is concerned, are presented in Table 1. According to the results presented in Table 1 there was a reduction (from $0.9 \%$ to $3 \%$ ) in fuel consumption in the three scenarios. The third scenario (HOV lane for passenger cars and Public Transport buses) is proved to be the most preferable one in terms of fuel consumption.

Within the framework of the research which was carried out in the Faculty of Rural and Surveying Engineering, Aristotle University of Thessaloniki [5], a scenario including the implementation of a HOV lane in the most heavily congested arterial (Tsimiski Str.) in the central area of the city of Thessaloniki is evaluated with the aid of SATURN. Tsimiski Str. is a one-way, heavily congested, street with four lanes one of which is a bus lane. Special consideration was given to the impact of the proposed scheme to fuel consumption. The results are based on the examination of the following two scenarios:

- "Before" scenario: Tsimiski Str. without HOV Lane (3 lanes for all vehicles)

- "After" scenario: Tsimiski Str. with HOV Lane (and 2 lanes for other vehicles)

Table 2: Values of fuel consumption in the "before" and "after" situation for all types of vehicles (morning peak period) in the city centre.

\begin{tabular}{|c|c|c|c|}
\hline & $\begin{array}{c}\text { "Before" } \\
\text { situation }\end{array}$ & $\begin{array}{c}\text { "After" } \\
\text { situation }\end{array}$ & $\begin{array}{c}\text { Difference } \\
\text { (\%) }\end{array}$ \\
\hline \multicolumn{3}{|c|}{ Values of the indicator for all types of vehicles in the city centre } \\
\hline Fuel consumption (lit) & $27,458.5$ & $30,997.9$ & 12.89 \\
\hline
\end{tabular}

Source: [5].

Table 3: Values of fuel consumption in the "before" and "after" situation for all types of vehicles (morning peak period) on Tsimiski Str.

\begin{tabular}{|c|c|c|c|c|c|}
\hline & $\begin{array}{c}\text { "Before" } \\
\text { situation }\end{array}$ & $\begin{array}{c}\text { "After" } \\
\text { situation }\end{array}$ & $\begin{array}{c}\text { Difference } \\
(\%)\end{array}$ & $\begin{array}{c}\text { HOV } \\
\text { lane }\end{array}$ & $\begin{array}{c}\text { Difference } \\
(\%)\end{array}$ \\
\hline $\begin{array}{c}\text { Total Fuel } \\
\text { Consumption } \\
\text { (lit) }\end{array}$ & 2,138 & 2,210 & 3.37 & 496 & - \\
\hline
\end{tabular}

Source: [5].

Table 2 presents the values of fuel consumption in the "before" and "after" situation for all types of vehicles (morning peak period) in the city centre. The results presented in Table 2 show that there is a substantial increase in the "after" 
situation $(+12.89 \%)$. Table 3 presents the values of fuel consumption in the "before" and "after" situation for all types of vehicles (morning peak period) on Tsimiski Str. The total fuel consumption (expresses in lit) is increased by $3.37 \%$.

\subsection{Proposed schemes for pedestrian-only streets, HOV lanes and bus-only streets in the city of Komotini}

The first case study refers to the city of Komotini, a medium size city situated in Northern Greece with a population of about 50,000 inhabitants. The city faces severe environmental and traffic problems due to its insufficient road network and the absence of traffic and demand management measures, which lead to an overall poor performance of the transport system. An extensive pedestrianization scheme was proposed, amongst other measures, for the city of Komotini concerning the two main streets passing nowadays through the city centre. This scheme was proposed in order to create an integrated network of pedestrian streets and also to provide an acceptable level for pedestrian trips in the city in terms of environment and safety.

The pedestrianization scheme was evaluated in terms if its traffic and environmental impacts [6], through the use of the traffic simulation and assignment model SATURN. The values of the parameters were calculated for the city road network both "before" and "after" the implementation of the proposed pedestrianization scheme. The SATURN road network consists of 44 nodes and 110 links. The area mostly affected by the implementation of this scheme includes the two directional links 100-104 and 104-103, which inevitably deliver the traffic from the pedestrian streets, since no construction of new roads is foreseen. The evaluation results as far as the fuel consumption is concerned are presented in Table 4 hereinafter.

Table 4: Comparison of Public Transport system fuel consumption for the whole network.

\begin{tabular}{|l|c|c|c|}
\hline $\begin{array}{l}\text { Comparison } \\
\text { element }\end{array}$ & $\begin{array}{c}\text { "Before" } \\
\text { situation }\end{array}$ & $\begin{array}{c}\text { "After" } \\
\text { situation }\end{array}$ & $\begin{array}{c}\text { Difference } \\
(\%)\end{array}$ \\
\hline \multicolumn{4}{|c|}{ Public Transport system data } \\
\hline $\begin{array}{c}\text { Fuel consumption } \\
\text { (lit) }\end{array}$ & 9.7 & 10.7 & +10.31 \\
\hline
\end{tabular}

Source: [6].

As it can be seen in Table 4 the Public Transport system was significantly affected, mainly due to the lack of sufficient road network for alternative routes. The construction of new roads in the periphery of the centre and also in the suburbs seems to be the only solution to this problem. Fuel consumption in the near area of pedestrianization scheme and also in the whole city road network is presented in Table 5. Finally, fuel consumption has been increased, both in the whole city road network and the near area of the pedestrianization scheme. 
Table 5: Comparison of fuel consumption before and after the implementation of the pedestrianization scheme.

\begin{tabular}{|c|c|c|c|c|}
\hline From Node & To Node & \multicolumn{2}{|c|}{ Fuel consumption (lit) } & \multirow{2}{*}{ Difference (\%) } \\
\cline { 3 - 4 } & $\begin{array}{c}\text { "Before" } \\
\text { situation }\end{array}$ & $\begin{array}{c}\text { "After" } \\
\text { situation }\end{array}$ & \\
\hline 100 & 104 & 5 & 7 & +40.0 \\
\hline 104 & 100 & 4 & 8 & +100.0 \\
\hline 104 & 103 & 11 & 11 & +0.0 \\
\hline 103 & 104 & 6 & 10 & +66.7 \\
\hline \multicolumn{2}{l}{$\begin{array}{l}\text { Total fuel consumption } \\
\text { in the network }\end{array}$} & 1174.1 & 1201.0 & +2.29 \\
\hline
\end{tabular}

Source: [6].

Table 6: Comparison of performance indicators for all traffic and for buses only.

\begin{tabular}{|c|c|c|c|}
\hline Comparison element & $\begin{array}{c}\text { "Before" } \\
\text { situation }\end{array}$ & $\begin{array}{c}\text { "After" } \\
\text { situation }\end{array}$ & Difference (\%) \\
\hline \multicolumn{4}{|c|}{ Performance indicator for buses } \\
\hline \multicolumn{4}{|c|}{ (whole city network) } \\
\hline Fuel consumption (lit) & 9,7 & 9,4 & $-3,09$ \\
\hline
\end{tabular}

Source: [7].

Table 7: Comparison of fuel consumption "before" and "after" the implementation of the scheme.

\begin{tabular}{|c|c|c|c|c|}
\hline \multirow{2}{*}{ From Node } & \multirow{2}{*}{ To Node } & \multicolumn{2}{|c|}{ Fuel consumption (lit) } & \multirow{2}{*}{$\begin{array}{c}\text { Difference } \\
(\%)\end{array}$} \\
\cline { 3 - 4 } & & "Before" & "After" & -32 \\
\hline 5 & 4 & 50 & 34 & $-26,32$ \\
\hline 4 & 5 & 19 & 14 & $-8,33$ \\
\hline 4 & 16 & 24 & 22 & $-20,45$ \\
\hline 16 & 4 & 44 & 35 & $-7,14$ \\
\hline 16 & 103 & 14 & 13 & $-14,29$ \\
\hline 103 & 16 & 7 & 6 & $-34,21$ \\
\hline 103 & 3 & 38 & 25 & $-42,31$ \\
\hline 3 & 8 & 26 & 15 & $-42,42$ \\
\hline 8 & 3 & 33 & 19 & $-33,33$ \\
\hline 8 & 108 & 9 & 6 & $-22,73$ \\
\hline 108 & 20 & 22 & 17 & $-24,24$ \\
\hline 20 & 5 & 33 & 25 & $-21,26$ \\
\hline
\end{tabular}

Source: [7].

The second case study which was examined for the central area of the city of Komotini includes an extensive and exclusive central road network for buses together with the introduction of HOV lanes (three or more passengers) [7]. The 
traffic simulation and assignment model that was used for the evaluation of the scheme was SATURN. It must be mentioned that the proposed scheme concerns the whole central area of the city. The area was represented in the SATURN road network by the two - directional links from node 5 to node 103 and from node 3 to node 8 and the one-way links 103-3 and 8-5. The values of the performance indicators were calculated for the city road network both "before" and "after" the implementation of the proposed scheme. The environmental parameters examined include emissions of pollutants and fuel consumption. The comparison of Public Transport system fuel consumption for the whole road network is presented in Table 6 .

As it is shown in Table 6, the fuel consumption for Public Transport buses in the "after" situation has been slightly reduced. Fuel consumption in the area of the scheme and also in the whole city road network is presented in Table 7.

Fuel consumption has been decreased, both in the whole city road network and the scheme implementation area. Values for fuel consumption after the implementation of the scheme are presented in Figure 1.

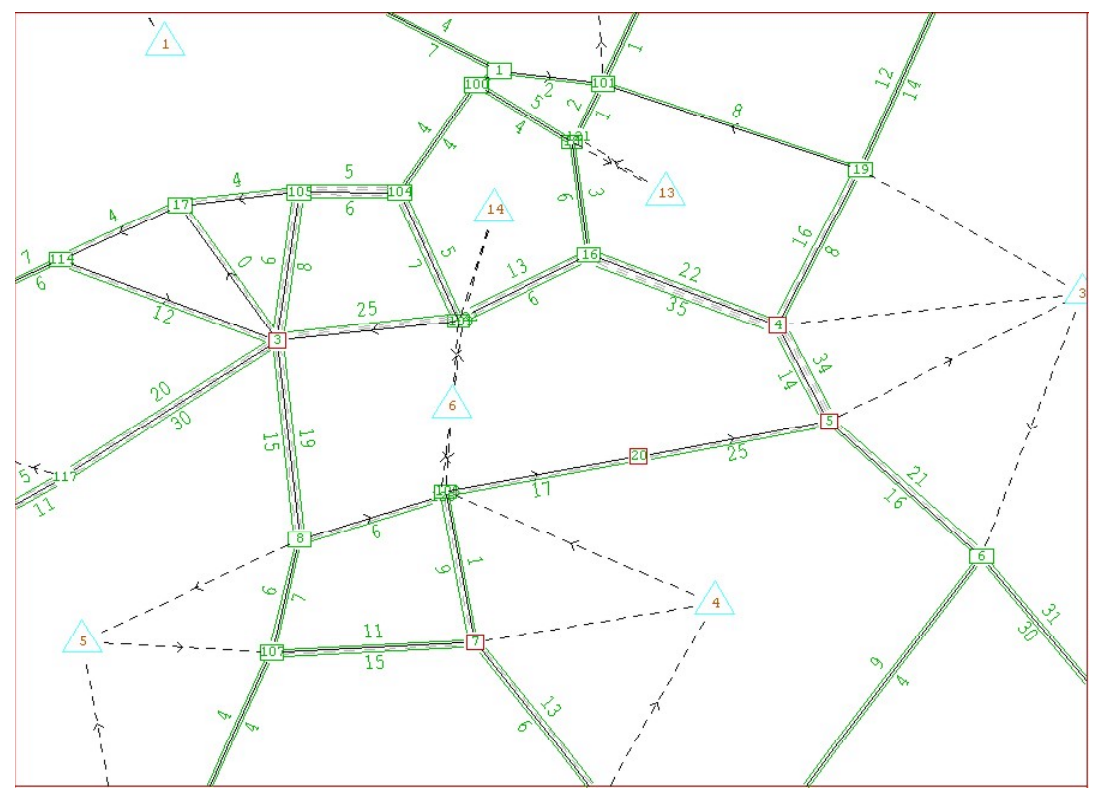

Source: [7].

Figure 1: $\quad$ Fuel consumption (lit) after the proposed scheme.

\subsection{Implemented with-flow bus lane and proposed contra-flow bus lane in the city of Thessaloniki}

An existing with-flow bus lane in the central area of Thessaloniki (along the Egnatia Rd.) was evaluated in terms of its traffic and environmental impacts with the use of SATURN model [8]. Values of the fuel consumption for the "before" 
and "after" situation are presented in Tables 8 and 9 respectively. Results show that there is a significant reduction in fuel consumption for both morning and afternoon peak period.

Table 8: Values if indicators in the "before" and "after" situation for buses only (morning peak period) in the city centre.

\begin{tabular}{|l|c|c|c|}
\hline & $\begin{array}{c}\text { "Before" } \\
\text { situation }\end{array}$ & $\begin{array}{c}\text { "After" } \\
\text { situation }\end{array}$ & $\begin{array}{c}\text { Difference } \\
(\%)\end{array}$ \\
\hline \multicolumn{4}{|c|}{ Values of indicator for buses in the city center } \\
\hline Fuel consumption (lit) & 1076,3 & 815,6 & $-24,22$ \\
\hline
\end{tabular}

Source: [8].

Table 9: Values if indicators in the "before" and "after" situation for buses only (afternoon peak period) in the city centre.

\begin{tabular}{|l|c|c|c|}
\hline & $\begin{array}{c}\text { "Before" } \\
\text { situation }\end{array}$ & $\begin{array}{c}\text { "After" } \\
\text { situation }\end{array}$ & $\begin{array}{c}\text { Difference } \\
(\%)\end{array}$ \\
\hline \multicolumn{4}{|c|}{ Values of indicator for buses in the city center } \\
\hline Fuel consumption (lit) & 949,2 & 680,4 & $-28,32$ \\
\hline
\end{tabular}

Source: [8]

Another case study which concerns the proposal of a contra-flow bus lane in the central area of Thessaloniki was examined in the framework of a research carried out in the Faculty of Rural and Surveying Engineering, Aristotle University of Thessaloniki [9]. The objective of the research was to assess the traffic and environmental impacts of the contra-flow bus lane along Tsimiski Str. which is a major one-way street in the central area. The evaluation was made through the use of the traffic simulation and assignment model SATURN.

The values of the fuel consumption for the "before" and "after" situation for the peak hour are presented in Table 10. As it is shown in Table 10, there is an increase in fuel consumption for buses due to the fact that they need to travel a longer distance in the "after" situation in order to enter the contra-flow bus lane. Fuel consumption for all types of vehicles is slightly reduced.

Table 10: Fuel consumption values in the "before" and "after" situation for all types of vehicles and for buses only (peak hour).

\begin{tabular}{|c|c|c|c|}
\hline & $\begin{array}{c}\text { "Before" } \\
\text { situation }\end{array}$ & $\begin{array}{c}\text { "After" } \\
\text { situation }\end{array}$ & $\begin{array}{c}\text { Difference } \\
(\%)\end{array}$ \\
\hline \multicolumn{4}{|c|}{ Values of indicator for all types of vehicles } \\
\hline Fuel consumption (lit) & 46907,6 & 46138,5 & $-1,67$ \\
\hline \multicolumn{4}{|c|}{ Values of indicator for buses } \\
\hline Fuel consumption (lit) & 990,6 & 1071,7 & 7,57 \\
\hline
\end{tabular}


Table 11: Fuel consumption along selected links in Tsimiksi Str.

\begin{tabular}{|c|c|c|c|c|c|c|c|}
\hline \multicolumn{8}{|c|}{ Fuel Consumption-lit/h } \\
\hline Route & Link & \multicolumn{2}{|c|}{$\begin{array}{l}\text { Do Nothing } \\
\text { scenario }\end{array}$} & \multicolumn{2}{|c|}{$\begin{array}{c}\text { Contraflow } \\
\text { scenario } \\
\end{array}$} & \multicolumn{2}{|c|}{$\begin{array}{c}\text { Mixed } \\
\text { scenario }\end{array}$} \\
\hline \multirow{16}{*}{$\begin{array}{l}\text { Tsimiski } \\
\text { Str. }\end{array}$} & $154-153$ & 43.00 & - & 43.00 & 0.00 & 44.00 & 2.33 \\
\hline & $152-151$ & 107.00 & - & 43.00 & -59.81 & 43.00 & -59.81 \\
\hline & $151-150$ & 191.00 & - & 115.00 & -39.79 & 138.00 & -27.75 \\
\hline & 149-312 & 162.00 & - & 30.00 & -81.48 & 30.00 & -81.48 \\
\hline & $312-148$ & 145.00 & - & 166.00 & 14.48 & 153.00 & 5.52 \\
\hline & $148-147$ & 182.00 & - & 187.00 & 2.75 & 188.00 & 3.30 \\
\hline & $147-146$ & 262.00 & - & 156.00 & -40.46 & 164.00 & -37.40 \\
\hline & $146-145$ & 237.00 & - & 48.00 & -79.75 & 50.00 & -78.90 \\
\hline & $145-144$ & 262.00 & - & 142.00 & -45.80 & 155.00 & -40.84 \\
\hline & 144-143 & 252.00 & - & 53.00 & -78.97 & 206.00 & -18.25 \\
\hline & $142-141$ & 50.00 & - & 77.00 & 54.00 & 80.00 & 60.00 \\
\hline & $141-140$ & 22.00 & - & 27.00 & 22.73 & 26.00 & 18.18 \\
\hline & $140-139$ & 97.00 & - & 125.00 & 28.87 & 119.00 & 22.68 \\
\hline & $164-173$ & 76.00 & - & 77.00 & 1.32 & 48.00 & -36.84 \\
\hline & $173-190$ & 10.00 & - & 10.00 & 0.00 & 10.00 & 0.00 \\
\hline & $190-203$ & 35.00 & - & 36.00 & 2.86 & 36.00 & 2.86 \\
\hline
\end{tabular}

The values of the fuel consumption along selected links in Tsimiksi Str. are presented in Table 11 (where the mixed scenario includes the implementation of the contra-flow bus lane together with the implementation of a with-flow bus lane in a major street (Stratou Str.) in the eastern part of the city centre).

\section{Discussion}

Transport Demand Management (TDM) strategies have been proved to be a useful tool towards the confrontation of traffic and environmental associated problems in central urban areas. The evaluation of the impacts of HOV lanes with the aid of the traffic and assignment model SATURN shows that fuel consumption is either decreased or increased, something which depends on the location of the HOV lane and the efficiency of the support measures. Pedestrianonly streets may lead to increase of fuel consumption if there are not sufficient alternative routes for the vehicular traffic. The combination of bus-only streets with HOV lanes seem to lead to the reduction of fuel consumption in central areas. The implementation of with-flow bus lanes lead to significant reduction of fuel consumption for buses while the implementation of contra-flow bus lanes has no clear positive effect unless appropriate support measures (e.g., efficient connection of the contra-flow bus lane with the rest of the bus network) are not taken. 


\section{References}

[1] European Commission, Directorate-General for Energy and Transport in cooperation with Eurostat, EU Energy and Transport in Figures, Statistical Pocketbook 2005.

[2] Department for Transport, Bus Priority - The Way Ahead, Resource Pack, Edition 2, December 2004.

[3] Victoria Transport Policy Institute, Online TDM Encyclopedia, www.vtpi.org/tdm

[4] Papaioannou, P. \& Georgiou, G., The implementation of an HOV lane in Thessaloniki: Impacts on traffic and the environment, Technika Chronika, Scientific Journal of the Technical Chamber of Greece, 21(1-3), pp. 191203, 2001.

[5] Basbas, S., Environmental evaluation of High Occupancy Vehicles (HOV) lanes, Fresenius Environmental Bulletin, 15(8a), pp. 791-797, 2006.

[6] Taxiltaris, C., Basbas S., Nikolaou K. \& Tzevelekis I., Environmental impact assessment of major pedestrianization schemes through the use of modelling techniques, Fresenius Environmental Bulletin, Vol.11 (10a), pp.800-805, 2002.

[7] Taxiltaris, C., Basbas, S., Nikolaou, K. \& Tzevelekis, I., The impact of transport demand management measures on urban environment and energy, Proc. of the $1^{\text {st }}$ Int. Conf. on Sustainable Energy, Planning \& Technology in relationship to the Environment, eds. C.A.Brebbia \& I.Sakellaris, WIT press, pp. 285-294, 2003.

[8] Basbas, S., Evaluation of bus lanes in central urban areas through the use of modelling techniques, Proc. of the $10^{\text {th }}$ Int. Conf. on Urban Transport and the Environment in the 21st Century - Urban Transport X, eds. C.A.Brebbia \& L.C.Wadhwa, WIT Press, pp. 389-397, 2004.

[9] Ligas, I. \& Massias, D., Traffic and environmental evaluation of bus lanes with the use of SATURN, Diploma thesis, Supervisor: Basbas, S., Department of Transportation and Hydraulic Engineering, Faculty of Rural and Surveying Engineering, Aristotle University of Thessaloniki, 2006. 